\title{
Prevention and treatment of acute and chronic radiodermatitis
}

This article was published in the following Dove Press journal:

Breast Cancer - Targets and Therapy

2 November 2017

Number of times this article has been viewed

\author{
Sophie Seité \\ René-Jean Bensadoun ${ }^{2}$ \\ Jean-Michel Mazer ${ }^{3}$ \\ 'La Roche-Posay Laboratoire \\ Dermatologique, Levallois-Perret, \\ ${ }^{2}$ Centre de Haute Energie (CHE), \\ Nice, ${ }^{3}$ Centre Laser International de \\ la Peau, Paris, France
}

\begin{abstract}
More than half the number of patients with cancer, who are treated with radiotherapy, will have radiodermatitis at some point during their treatment. Radiodermatitis either occurs early on in the treatment period or appears months or up to several years later. Acute radiodermatitis is a burn injury that varies in severity according to both treatment and inherent patient factors. Most acute radiodermatitis reactions resolve after several weeks but some reactions persist and can cause complications. Late-onset radiodermatitis is characterized by telangiectasia that forms on atrophic and fragile skin. These radiodermatitis reactions can have a significant negative impact on concomitant and subsequent therapeutic protocols and most particularly on the patient's quality of life. Today, treatment of radiodermatitis reactions is in its infancy. Although there is insufficient evidence available to form recommendations that would prevent or reduce radiodermatitis, some advances have been made using low level light therapy (LLLT) or vascular lasers to control the symptoms. Some recent preclinical and clinical research suggests that LLLT has biostimulating properties which allow the tissues to regenerate and heal faster, reduce inflammation, and prevent fibrosis. Also, in late-onset radiodermatitis pulsed dye laser treatment has been shown to be beneficial in clearing radiation-induced telangiectasia. In the absence of evidence-based recommendations, the objective of this paper is to review how to prevent or manage the symptoms of radiodermatitis reactions.
\end{abstract}

Keywords: acute radiodermatitis, chronic radiodermatitis, low level light therapy, laser, pulsed dye, prevention, management, skin care

\section{Introduction}

International data indicate that $50 \%$ of patients diagnosed with cancer will receive some form of radiation therapy. Radiodermatitis is a substantial side effect that arises directly from radiation exposure during cancer treatment, and concerns around 95\% of all cancer patients receiving radiation therapy. ${ }^{1,2}$ It is particularly problematic in cancers of the breast, perineum, and head and neck region, where the skin is part of the target volume. ${ }^{3}$

Radiodermatitis is referred to as being an acute reaction when it occurs around the time of therapy and either chronic or late onset when it appears 5-10 years after the end of treatment. Symptoms of acute radiodermatitis have been classified into three levels; grade 1 (mild erythema), grade 2 (dry desquamation), and grade 3 (severe moist desquamation). ${ }^{4}$ In recent years, skin sparing and modern equipment such as intensitymodulated radiation therapy reduced dose intensity on the skin and new equipment has reduced the severity of acute radiodermatitis for many patients. ${ }^{5}$ Nevertheless,
Correspondence: Sophie Seité La Roche-Posay Laboratoire Dermatologique, 62 Quai Charles Pasqua, 92300 Levallois-Perret, France Tel +33 | 49643340

Email sophie.seite@loreal.com
Breast Cancer - Targets and Therapy 2017:9 55I-557 
grade 1 skin toxicity still remains a problem for around $90 \%$ of patients and grade 2 for $30 \%$ of patients. ${ }^{6}$ While radiodermatitis may resolve over time, it can profoundly affect the patient's quality of life and may limit the treatment duration and dose delivered. ${ }^{2}$

Chronic radiodermatitis occurs in a third of all patients and appears up to at least 10 years after radiotherapy treatment. ${ }^{7}$ Typical symptoms are telangiectasia, pigmentation, cutaneous atrophy (dry papery skin), dermal sclerosis, and keratoses. ${ }^{4}$ Chronic radiodermatitis is an increasing problem, as today $>80 \%$ of all women treated for breast cancer are now surviving for $\geq 10$ years. ${ }^{8}$

Fortunately, there are several solutions available today to prevent and treat radiodermatitis and skin reactions. Dermocosmetic support is recommended to protect and promote tissue repair; light technology, such as biophotomodulation and vascular laser treatments, is becoming established as safe and effective to protect and treat both acute and chronic radiodermatitis. ${ }^{9,10}$

The objective of this review paper is to provide an overview of the different types of radio and combined chemotherapy-induced radiodermatitis and highlights the evidence for management and treatment.

\section{Radiodermatitis}

Radiodermatitis is the result of cutaneous or subcutaneous lesions induced by external beam radiation. The skin is particularly sensitive to radiation damage because it is a continuously renewing organ. In healthy skin tissue, there is a delicate balance between the death and rebirth of each cell type. Acute radiation damage occurs in the dermis with the first radiation dose. A number of basal keratinocytes are destroyed, leaving only the remaining keratinocytes to cornify. Thus, the balance between the normal cell production at the basal layer and cell destruction at the skin surface is disrupted. This process continues with continuing radiation thereby altering the integrity of the epidermis, the skin barrier, and skin healing processes. This leads to structural, histologic, and vasculature changes of the skin and underlying connective tissue. ${ }^{11}$

With cumulative radiation doses, these acute injuries become apparent. The skin barrier dysfunction manifests as erythema, skin dryness, flaking, folliculitis (skin rash), xerosis, pruritus, and hyperpigmentation. Additionally, the physical barrier and cutaneous immune system are compromised and the skin becomes more sensitive to allergens, ultraviolet radiation, and infection. ${ }^{12}$

Some cutaneous cell types grow and renew themselves rapidly and in others the life cycle is slower. Radiation affects these two populations differently and the probability of destroying a skin cell increases with the level of radiation. Thus, it is possible to have different types of skin reactions occurring at the same time postradiation depending on which cell types have been affected. ${ }^{13}$

\section{Supportive dermocosmetic skin care for patients starting radiotherapy}

Regular skin care assessment and close collaboration between radiation oncologists and dermatologists to manage skin reactions early and throughout treatment have been repeatedly suggested to improve patient comfort, enhance quality of life, and improve clinical outcome. ${ }^{14-16}$ However, there is little evidence concerning skin care products to alleviate the severity of skin reactions. ${ }^{17}$

One recent, multinational, real-life study to evaluate a combination of hygiene products was performed in women starting radiotherapy following breast cancer. The objective was to evaluate the tolerance of a specific dermocosmetic regimen on the irradiated area and the effectiveness in delaying or reducing the intensity of acute radiodermatitis. This was measured by erythema, edema, skin dryness, desquamation, physical appreciation, and patient appreciation using the patient benefit index at the start and end of treatment $(6 \pm 2$ weeks). ${ }^{18}$ Patients were provided with a dermocosmetic kit before the first radiotherapy session. The kit included five products specifically formulated with gentle ingredients that respect skin physiology and tested for use on sensitive skin. In total, 253 women were included in the study, following a tumor excision, partial or full mastectomy. The results revealed two categories of users who were defined by the number $(0-5)$ and frequency of products used (never, sometimes, often, and every day). Low users made up $36 \%$ of the study group and $57 \%$ were heavy users. This study shows that this skin care regimen was well tolerated on irradiated skin and heavy product users observed less frequent radiodermatitis reactions than low product users (Figure 1). These results were further supported by a recent conference communication that found that the frequency of severe (grade 3 or 4) radiodermatitis was significantly lower in the intervention group (chi-square $=4.61 ; p=0.03$ ), although the time to onset of skin toxicity was similar among the intervention group compared with a previous cohort (median time to onset, 17 vs 17.5 days), ${ }^{19}$ thus indicating that patient education can improve adherence to skin care plans and reduce radiation dermatitis. These reports continue to provide support for international recommendations for supportive skin care in radiotherapy. 


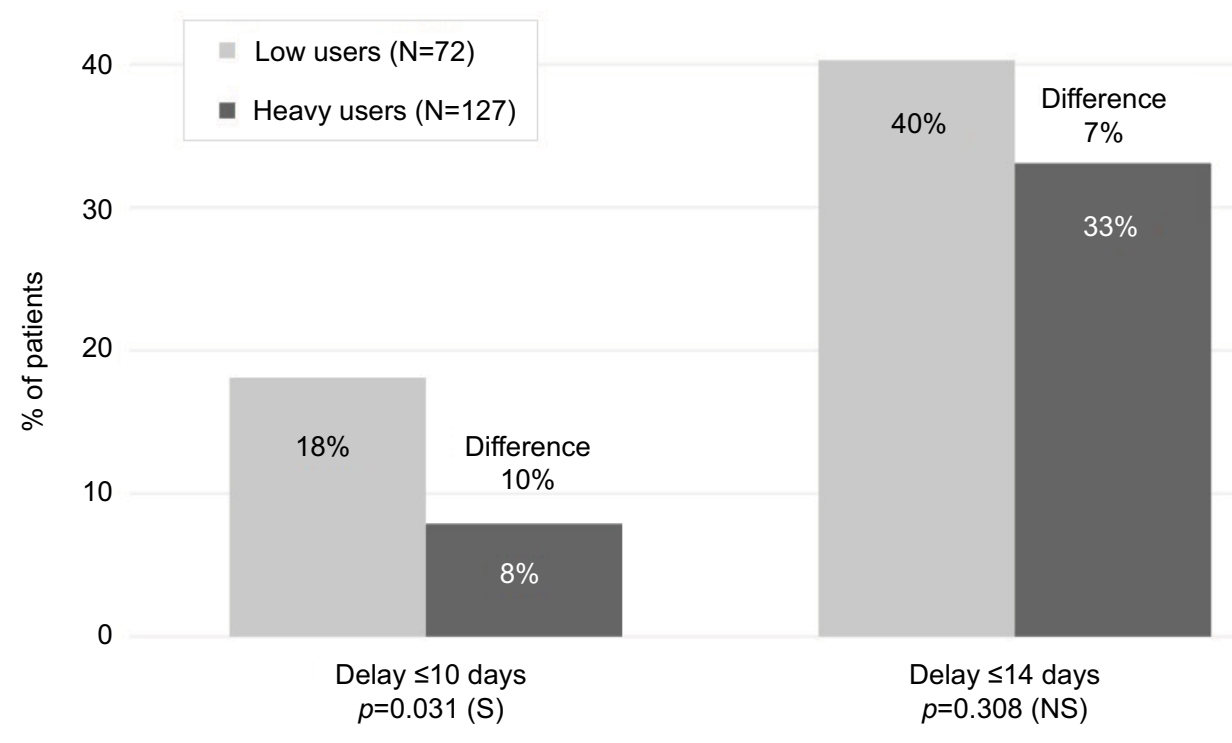

Figure I Time to onset of radiodermatitis from radiotherapy start. Abbreviations: S, significant; NS, non significant.

\section{Acute radiodermatitis}

Acute radiodermatitis is a burn injury that varies in severity according to both treatment and inherent patient factors. ${ }^{1}$ Treatment-related factors that influence the degree to which skin tissues are damaged include the total dose, fractionation, type and quality of the beam, and surface area and volume of tissue exposed. ${ }^{11}$ Also, certain anatomical regions where the target is close to the skin are more susceptible to developing radiodermatitis. These areas include skin folds around the breast and inguinal areas, thin cutaneous regions (clavicle, periauricular area, or axilla), mucosal regions (vulva, anus, and mouth), or altered skin following a previous treatment.

Concomitant radiotherapy with chemotherapy such as epidermal growth factor receptor (EGFR) inhibitors seems to increase the intensity of the EGFR inhibitors-induced rash and delays the appearance by $2-5$ weeks after the beginning of treatment. ${ }^{20-22}$

Typical radiotherapeutic treatment such as a dose intensity of 20 Gy with conventional fractionation (2 Gy/fraction; five fractions/week) results in sustained erythema that usually appears between 10 and 14 days after radiotherapy. ${ }^{23}$ Although most acute radiodermatitis reactions resolve after 2-3 weeks, some reactions persist and can cause complications such as treatment delays, diminished esthetic appeal, and reduced quality of life. ${ }^{2,24,25}$

\section{Treatment of acute radiodermatitis}

Today, there is insufficient evidence available to form recommendations that would prevent or reduce radiodermatitis. However, several multidisciplinary groups have proposed guidelines that suggest management strategies with the objective to avoid or reduce the severity of radiodermatitis reactions: Association Francophone des Soins Oncologiques de Support, ${ }^{26}$ Multinational Association of Supportive Care in Cancer, ${ }^{4}$ European Skin Management in Oncology, ${ }^{16}$ and consensus guidelines for the management of radiodermatitis and coexisting acne-like rash. ${ }^{21,27}$ Nevertheless, many centers develop their own protocols.

The general recommendations are presented in Table 1. Low level light therapy (LLLT), otherwise known as photobiomodulation (PBM) or "soft laser" (red light or infrared, power $<150 \mathrm{~mW}$ ), is better known in dermatology to treat ulcers. ${ }^{28}$ However, the biological mechanisms behind the therapeutic effect are currently not well understood. Recent molecular and cellular research suggests that LLLT has biostimulating properties which allow the tissues to regenerate and heal faster. ${ }^{910}$ Animal and clinical studies suggest that LLLT has analgesic properties, reduces inflammation, and prevents fibrosis. ${ }^{29-31}$

Treating radiodermatitis with LLLT is based on previously demonstrated decreased severity and duration of oral mucositis. ${ }^{32-34}$ However, its preventative and curative use in acute radiodermatitis is currently under evaluation. It was reported that the incidence of radiodermatitis reduced with light emitting diode treatments immediately after radiation therapy for breast cancer. However, a further controlled clinical study was unable to reproduce the results. ${ }^{35}$ Nevertheless, based on the strong level of evidence available, Bensadoun and Nair proposed a protocol to prevent or treat radiation dermatitis using LLLT. The authors suggest that laser therapy can be 
Table I General recommendations

\section{General advice}

- Skin cleansing

- Liquid soap or dermatological soap bar with a $\mathrm{pH}$ close to 5 , without perfume, plant or fruit extracts

o Dry skin delicately but meticulously

- Skin hydration

o Apply a non-comedogenic emollient cream without perfume, lanoline, I or 2 times per day, preferably after the radiotherapy session

o Avoid applying topical creams to the radiation zone at least I hour before the radiotherapy session. This will avoid a bolus effect (increased radiation dose delivered to the epidermis)

- Photoprotection

o Protect the irradiated skin zone from sun exposure

o Apply a sunscreen SPF 50+ with UVA /UVB protection.

- Clothing

- Wear ample, soft cotton clothing

o Avoid wearing synthetic clothes

- Additional advice

o Use an electric razor and do not shave too close to the skin.

- Avoid applying products that contain alcohol (perfume, eau de toilette, ether, talcum powder)

o Avoid applying sticky plaster

o Avoid rubbing or scratching

\section{Acute radiodermatitis}

\section{Grade I}

Mild to moderate erythema

Desquamation dry and moderately sensitive

\section{Grade 2}

Intense sensitive and mildly painful erythema

Moist lesions confined to skin folds

Edema

\section{Grade 3}

Intense, painful erythema

Extensive weeping moist zones larger than skin

fold areas

Bleeding wounds
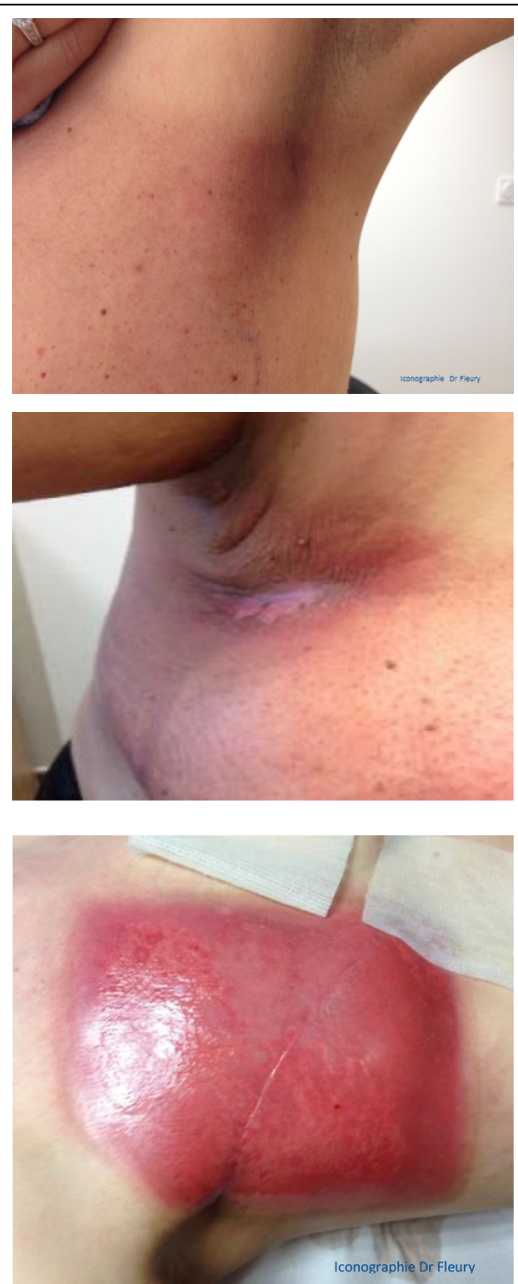

- Follow local hygiene routine

If needed:

- Emollient cream

- Topical corticotherapy

- Protective hydrogel, hydrobalance hydrocellular dressing

- Avoid "Tulle gras" dressing

- Low-energy laser (currently under evaluation)

- Continue local hygiene routine

If needed:

- Emollient cream

- Healing cream, acid hyaluronic cream

- Topical corticosteroid

- Drying lotion

- Absorbent, nonadhesive, protective dressing (hydrogel, hydrocellular, hydrobalance)

- Expose to fresh air as much as possible

- Avoid antibacterial application

- Low-energy laser (currently under evaluation)

If needed:

Clean the wound with physiological serum

- Tulle gras dressing I or 2 times a day

- Nonadhesive, absorbent dressings, hydroabsorbant, hydrocellular

- Alginate dressing if bleeding

- Hydrofiber dressing if abundant exudate

After radiotherapy

- Continue using nonirritant local skin care, emollient, and sunscreen

- Avoid wearing constricting clothing, synthetic fabric for several weeks

- Watch daily for life 
started after only a few radiation sessions and before erythema appears or even after erythema has appeared. The treatment was shown to be painless and can be practiced thrice per week, either before or after the radiotherapy session. ${ }^{36}$ More recently, Censabella et al performed an open, prospective, comparative study and found that skin toxicity improved significantly following multiwave locked system ${ }^{\circledR}$ laser therapy. ${ }^{37}$

\section{Chronic radiodermatitis}

Chronic radiodermatitis, otherwise referred to as late reaction, is characterized by its highly variable, delayed apparition. This late-onset reaction can appear from 6 months up to 20 or 30 years after treatment and can reappear when provoked by the administration of a different treatment such as chemotherapy or antibiotics. The frequency and severity have been shown to be linked with the total dose $(+50$ Gy to the skin) and favored by short treatment intervals, limited fraction size, large treatment areas, and tumor infiltrate. Other external factors that aggravate chronic radiodermatitis include repetitive trauma, sun exposure, and further irradiation. Chronic radiodermatitis is dominated by telangiectasia that forms on atrophic and fragile skin, associated with areas of hyper or hypopigmentations. ${ }^{38}$ Less commonly, a more severe form of delayed radionecrosis occurs where the skin sits close to bone or cartilage such as the nose, ears, or scalp. ${ }^{23}$

Pulsed dye laser treatment has been shown to be beneficial in clearing radiation-induced telangiectasia. The first prospective study reported by Lanigan et al was performed on eight individuals. This study demonstrated that lesions could be whitened using very short pulse durations $(0.45 \mathrm{~ms})$ using a $585 \mathrm{~nm}$ pulsed dye laser. ${ }^{38}$ The study was later supported by a larger comparative study with 13 participants that compared three sessions of either pulsed dye laser or pulsed intense light laser. Patients treated with the pulsed dye laser had a reduction in lesion size of $90 \%$, compared to $50 \%$ with the intense pulsed light (IPL). IPL systems are high-intensity light sources, which emit polychromatic light. Unlike laser systems, IPL works with noncoherent light in a broad wavelength spectrum of 515-1200 nm. Both procedures were well tolerated, except for one case of achromia with the IPL. ${ }^{39}$ Furthermore, over a number of years, Dr JM Mazer performed several open clinical studies on large patient numbers to further refine the number treatment modality (Figure 2). ${ }^{40}$ The first study included 110 women, treated with a pulsed dye vascular laser (ScleroPlus laser [Candela] followed by Vbeam laser [Candela]) at $1.5 \mathrm{~ms}$ pulse duration, wavelength $595 \mathrm{~nm}$, with a spot size diameter of $7 \mathrm{~mm}$, and fluence of 9-11.5 J/ $\mathrm{cm}^{2}$. Between one and five sessions were required to reduce the number of telangiectasias
A

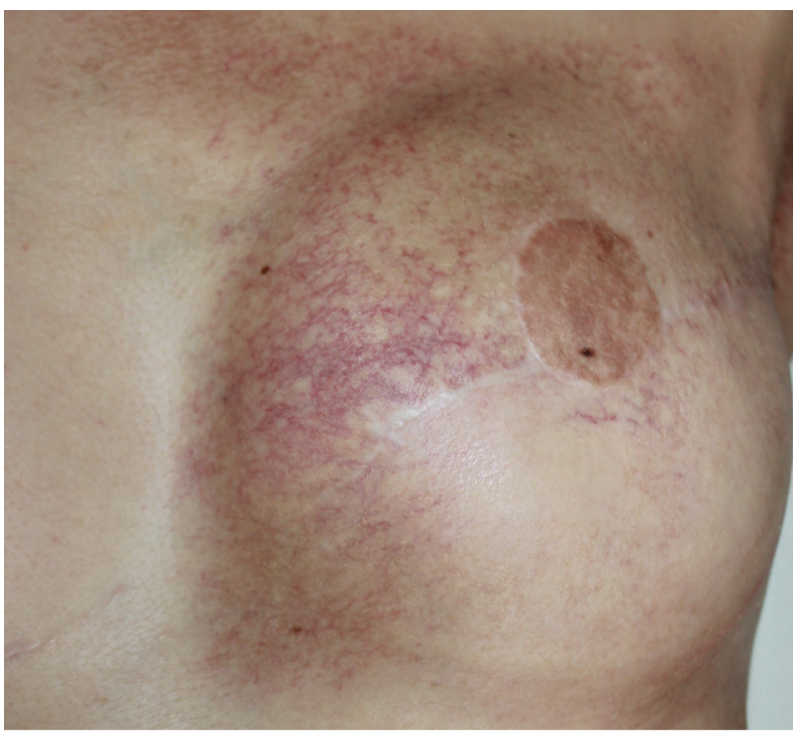

B

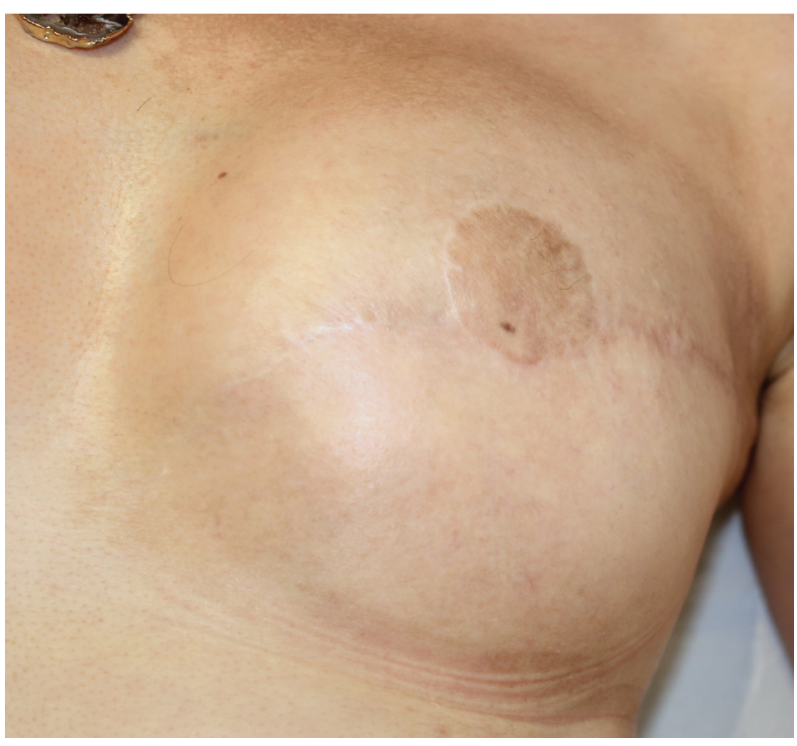

Figure 2 Example of results obtained after two sessions of vascular laser and two sessions of fractional non-ablative laser.

Note: (A) Before treatment; (B) after treatment.

by $80 \%$. A second study was performed with a more recent pulsed dye laser (Vbeam Perfecta laser [Candela]) comparing 1.5 to $6 \mathrm{~ms}$ pulse durations, with purpuragenic fluences, for the same spot size diameter and the same wavelength of $595 \mathrm{~nm}$. The number of patients included for post-breast cancer radiotherapy was 176, presenting a total of 234 different lesions, 144 on the presternal area and 90 on the lateral side of the breast. The main criterion of efficacy was the number of needed sessions to obtain $80 \%$ reduction in telangiectasias, according to both the patient and the physician. The objective was to investigate if longer pulse durations would be more effective on more dilated vessels, typical of radiodermatitis, according 
to the rules of selective photothermolysis. However, although the efficacy was satisfactory for both pulse times, the shorter pulse durations were more effective: all patients obtained at least $80 \%$ regression in telangiectasia, after two or three sessions for $84 \%$ of cases with the $1.5 \mathrm{~ms}$, and in less than five sessions in $95 \%$ of cases. ${ }^{41}$ Pulsed dye laser has been shown to be safe and well tolerated in this population with particularly atrophied skin. Purpura resolved within 10-15 days. No further supportive care is required apart from sunscreen for at least 6 weeks following the procedure. No severe side effects were observed, neither scars nor skin necrosis nor ulceration. Patients reported a significant improvement in quality of life. The physicians noticed an improved skin thickness, probably related to the remodeling effect, known with this laser. The authors suggested that other lasers, particularly fractional ablative lasers or, on this fragile skin, non-ablative lasers, could be effective in reducing atrophy and improving the skin texture.

\section{Conclusion}

Today, there is increasing evidence to support various strategies to limit and treat cutaneous reactions to radiotherapy. To prevent acute radiodermatitis, daily dermocosmetic use is useful from the beginning of radiotherapy. There is evidence for the efficacy of PBM to both prevent and cure acute radiodermatitis. In chronic radiodermatitis, treatment with vascular lasers, especially pulsed dye laser, using short pulse durations, has been shown to be effective with an excellent tolerance, inducing a better quality of life for the patients.

\section{Acknowledgment}

The authors thank Amanda Whereat of Speak the Speech Consulting for providing assistance to write this article. This article was funded by La Roche-Posay Laboratoire Dermatologique, France.

\section{Disclosure}

SS is an employee of La Roche-Posay Laboratoire Dermatologique, France. The authors report no other conflicts of interest in this work.

\section{References}

1. Chan RJ, Webster J, Chung B, Marquart L, Ahmed M, Garantziotis S. Prevention and treatment of acute radiation-induced skin reactions: a systematic review and meta-analysis of randomized controlled trials. BMC Cancer. 2014;14:53.

2. Deng G, Cassileth BR. Skin Injury: Acute Dermatitis and Chronic Skin Changes. Supportive Care and Quality of Life. 5th ed. Philadelphia, PA: Lippincott Williams \& Wilkins; 2008.

3. DeSantis CE, Lin CC, Mariotto AB, et al. Cancer treatment and survivorship statistics, 2014. CA Cancer J Clin. 2014;64(4):252-271.
4. Wong RK, Bensadoun RJ, Boers-Doets CB, et al. Clinical practice guidelines for the prevention and treatment of acute and late radiation reactions from the MASCC Skin Toxicity Study Group. Support Care Cancer. 2013;21(10):2933-2948.

5. Pignol JP, Olivotto I, Rakovitch E, et al. A multicenter randomized trial of breast intensity-modulated radiation therapy to reduce acute radiation dermatitis. J Clin Oncol. 2008;26(13):2085-2092.

6. Chan RJ, Larsen E, Chan P. Re-examining the evidence in radiation dermatitis management literature: an overview and a critical appraisal of systematic reviews. Int J Radiat Oncol Biol Phys. 2012;84(3):e357-e362.

7. Whelan TJ, Pignol JP, Levine MN, et al. Long-term results of hypofractionated radiation therapy for breast cancer. $N$ Engl J Med. 2010;362(6): 513-520.

8. American Cancer Society. Cancer Facts \& Figures 2017. Atlanta: American Cancer Society; 2017. Available from: https://www.cancer. org/. Accessed OCtober 12, 2017.

9. Avci P, Gupta A, Sadasivam M, et al. Low-level laser (light) therapy (LLLT) in skin: stimulating, healing, restoring. Semin Cutan Med Surg. 2013;32(1):41-52.

10. Hashmi JT, Huang YY, Sharma SK, et al. Effect of pulsing in low-level light therapy. Lasers Surg Med. 2010;42(6):450-466.

11. Cox JD, Ang K. Radiation Oncology: Rationale, Technique, Results. 9th ed. Philadelphia, PA: Mosby Elsevier; 2010.

12. Ryan JL. Ionizing radiation: the good, the bad, and the ugly. $J$ Invest Dermatol. 2012;132(3 Pt 2):985-993.

13. Singh M, Alavi A, Wong R, Akita S. Radiodermatitis: a review of our current understanding. Am J Clin Dermatol. 2016;17(3):277-292.

14. McQuestion M. Evidence-based skin care management in radiation therapy: clinical update. Semin Oncol Nurs. 2011;27(2):e1-e17.

15. Bolderston A, Lloyd NS, Wong RK, Holden L, Robb-Blenderman L; Supportive Care Guidelines Group of Cancer Care Ontario Program in Evidence-Based Care. The prevention and management of acute skin reactions related to radiation therapy: a systematic review and practice guideline. Support Care Cancer. 2006;14(8):802-817.

16. Bensadoun RJ, Humbert P, Krutmann J, et al. Daily baseline skin care in the prevention, treatment, and supportive care of skin toxicity in oncology patients: recommendations from a multinational expert panel. Cancer Manag Res. 2013;5:401-408.

17. Kumar S, Juresic E, Barton M, Shafiq J. Management of skin toxicity during radiation therapy: a review of the evidence. J Med Imaging Radiat Oncol. 2010;54(3):264-279.

18. Blome C, Augustin M, Behechtnejad J, Rustenbach SJ. Dimensions of patient needs in dermatology: subscales of the patient benefit index. Arch Dermatol Res. 2011;303(1):11-17.

19. Andriths L. Educating breast cancer patients reduces radiation dermatitis severity. Paper presented at: Oncology Nursing Society (ONS) 42nd Annual Congress; 2017; Denver, CO, USA.

20. Bonner JA, Harari PM, Giralt J, et al. Radiotherapy plus cetuximab for squamous-cell carcinoma of the head and neck. $N$ Engl $J$ Med. 2006;354(6):567-578.

21. Bernier J, Bonner J, Vermorken JB, et al. Consensus guidelines for the management of radiation dermatitis and coexisting acne-like rash in patients receiving radiotherapy plus EGFR inhibitors for the treatment of squamous cell carcinoma of the head and neck. Ann Oncol. 2008;19(1):142-149.

22. Tejwani A, Wu S, Jia Y, Agulnik M, Millender L, Lacouture ME. Increased risk of high-grade dermatologic toxicities with radiation plus epidermal growth factor receptor inhibitor therapy. Cancer. 2009;115(6):1286-1299.

23. Hymes SR, Strom EA, Fife C. Radiation dermatitis: clinical presentation, pathophysiology, and treatment 2006. JAm Acad Dermatol. 2006;54(1): $28-46$.

24. Johansen J, Overgaard J, Rose C, et al. Cosmetic outcome and breast morbidity in breast-conserving treatment - results from the Danish DBCG-82TM national randomized trial in breast cancer. Acta Oncol. 2002;41(4):369-380. 
25. Arenas M, Sabater S, Hernandez V, et al. Cosmetic outcome of breast conservative treatment for early stage breast cancer. Clin Transl Oncol. 2006;8(5):334-338.

26. AFSOS. Toxicité cutanée radio-induit. [AFSOS radio-induced cutaneous toxicity]. 2014. Available from: http://www.afsos.org/fiche-referentiel/ toxicite-cutanee-radio-induite/. Accessed April 12, 2014. French.

27. Reguiai Z, Bachet JB, Bachmeyer C, et al. Management of cutaneous adverse events induced by anti-EGFR (epidermal growth factor receptor): a French interdisciplinary therapeutic algorithm. Support Care Cancer. 2012;20(7):1395-1404.

28. Mester A. Laser biostimulation. Photomed Laser Surg. 2013;31(6): 237-239.

29. Bjordal JM, Johnson MI, Iversen V, Aimbire F, Lopes-Martins RA. Low-level laser therapy in acute pain: a systematic review of possible mechanisms of action and clinical effects in randomized placebocontrolled trials. Photomed Laser Surg. 2006;24:158-168.

30. Luo L, Sun Z, Zhang L, Li X, Dong Y, Liu TC. Effects of low-level laser therapy on ROS homeostasis and expression of IGF-1 and TGFbeta1 in skeletal muscle during the repair process. Lasers Med Sci. 2013;28(3):725-734.

31. de Oliveira FA, Sanders-Pinheiro H. Low-level laser therapy decreases renal interstitial fibrosis. Photomed Laser Surg. 2013;31(10):507-508.

32. Clarkson JE, Worthington HV, Furness S, McCabe M, Khalid T, Meyer S. Interventions for treating oral mucositis for patients with cancer receiving treatment. Cochrane Database Syst Rev. 2010;8:CD001973.

33. Bjordal JM, Bensadoun RJ, Tuner J, Frigo L, Gjerde K, Lopes-Martins RA. A systematic review with meta-analysis of the effect of low-level laser therapy (LLLT) in cancer therapy-induced oral mucositis. Support Care Cancer. 2011;19(8):1069-1077.

34. Lalla RV, Bowen J, Barasch A, et al. MASCC/ISOO clinical practice guidelines for the management of mucositis secondary to cancer therapy. Cancer. 2014;120(10):1453-1461.
35. Fife D, Rayhan DJ, Behnam S, et al. A randomized, controlled, doubleblind study of light emitting diode photomodulation for the prevention of radiation dermatitis in patients with breast cancer. Dermatol Surg. 2010;36(12):1921-1927.

36. Bensadoun RJ, Nair RG. Low-level laser therapy in the management of mucositis and dermatitis induced by cancer therapy. Photomed Laser Surg. 2015;33(10):487-491.

37. Censabella S, Claes S, Robijns J, Bulens P, Mebis J. Photobiomodulation for the management of radiation dermatitis: the DERMIS trial, a pilot study of MLS $®$ laser therapy in breast cancer patients. Support Care Cancer. 2016;24(9):3925-3933.

38. Lanigan SW, Joannides T. Pulsed dye laser treatment of telangiectasia after radiotherapy for carcinoma of the breast. Br J Dermatol. 2003;148(1):77-79.

39. Nymann P, Hedelund L, Haedersdal M. Intense pulsed light vs. longpulsed dye laser treatment of telangiectasia after radiotherapy for breast cancer: a randomized split-lesion trial of two different treatments. $\mathrm{Br}$ J Dermatol. 2009;160(6):1237-1241.

40. Mazer JM. Indications pour les lasers médicaux en dermatologie. [Indications for medical lasers in dermatology]. Presse Med. 2002;31(5):223-231. French.

41. Mazer JM. Communication presentation. Presented at American Society for Laser Medicine and Surgery, Inc; Apr 05-09, 2017; San Diego, CA, USA.

42. Dreno B, Bensadoun RJ, Humbert P, et al. Algorithm for dermocosmetic use in the management of cutaneous side-effects associated with targeted therapy in oncology. J Eur Acad Dermatol Venereol. 2013;27(9): 1071-1080.

43. Lacouture ME. Mechanisms of cutaneous toxicities to EGFR inhibitors. Nat Rev Cancer. 2006;6(10):803-812.
Breast Cancer - Targets and Therapy

\section{Publish your work in this journal}

Breast Cancer - Targets and Therapy is an international, peerreviewed open access journal focusing on breast cancer research, identification of therapeutic targets and the optimal use of preventative and integrated treatment interventions to achieve improved outcomes, enhanced survival and quality of life for the cancer patient.

\section{Dovepress}

The manuscript management system is completely online and includes a very quick and fair peer-review system, which is all easy to use. Visit http://www.dovepress.com/testimonials.php to read real quotes from published authors. 